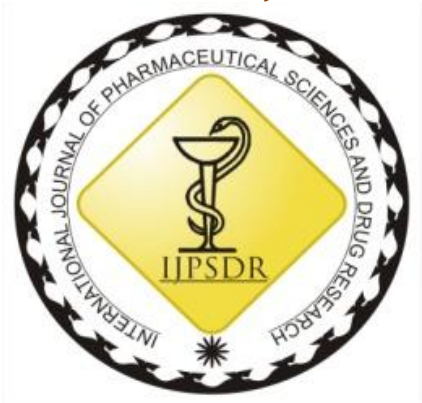

ISSN: 0975-248X

Review Article CODEN (USA): IJPSPP

(c)) EY-NG-SA

\title{
Liposomal Formulations in Cancer Therapy: Basic Concepts to Advanced Strategies
}

\author{
R. K Jani ${ }^{*}$, K. M Gohil \\ Department of Pharmaceutics, Faculty of Pharmacy, Parul Institute of Pharmacy and Research, Parul University, \\ Waghodia-391760, Vadodara, Gujarat, India
}

Copyright (c) 2018 R. K Jani et al. This is an open access article distributed under the terms of the Creative Commons AttributionNonCommercial-ShareAlike 4.0 International License which allows others to remix, tweak, and build upon the work non-commercially, as long as the author is credited and the new creations are licensed under the identical terms.

\begin{abstract}
Liposomes, a phospholipid bilayer vesicular system is extensively being used and studied for drug delivery applications in cancer therapy. The reason behind is advantages that liposomes offer such as their biocompatible and non-immunogenic nature, improved bioavailability of anticancer drugs and versatility of efficiently encapsulating both hydrophilic and hydrophobic drugs. Recent advances such as surface functionalization and modifications of liposomes have played very crucial part to overcome limitations associated with conventional liposomal system which eventually has opened up many new and potential ways of cancer therapy. Surface decoration of liposomes with targeting ligand can lead to actively targeted site specific therapy of solid tumor. Recently, a number of liposomal formulations for cancer treatment are already in clinic and many are still under active research. This review discusses about the basics of liposomes such as structural, components, methods of preparation, and mainly focuses on recent advances of liposomal technology which includes various kinds of surface modification of currently used liposomes with efficient passive or active targeted drug delivery along with its mechanism, the advantages and associated drawbacks and their potential applications in treatment of cancer.
\end{abstract}

Keywords: Liposomes, Targeted Drug Delivery, Cancer Therapy, Solid Tumor, Surface Modification.

*Corresponding author: Dr. Rupalben Kaushalkumar Jani

Address: Department of Pharmaceutics, Faculty of Pharmacy, Parul Institute of Pharmacy and Research, Parul University, At Post-Limda, Ta-Waghodia-391760, Dist-Vadodara, Gujarat, India

Tel.: +91-9427530251

E-mail $\bowtie$ : rupal.jani@paruluniversity.ac.in

Relevant conflicts of interest/financial disclosures: The authors declare that the research was conducted in the absence of any commercial or financial relationships that could be construed as a potential conflict of interest.

Received: 19 July, 2018; Revised: 20 August, 2018; Accepted: 23 August, 2018; Published: 23 September, 2018

\section{INTRODUCTION}

Cancer worldwide is a leading cause of death and is main concern for the health professionals throughout the globe. [1] Because of genetic mutations and diverging signals of different pathways related to the growth and survival of the cells, there is an uncontrolled growth of cells to develop cancer. [2] Extensive research is going on for cancer therapy amongst which liposomes as a drug or gene or protein and peptide delivery system has widely studied and found to be effective nanocarrier for anti-cancer agents in cancer therapy. Since many years, conventional 
liposomes have been efficaciously utilised in cancer therapeutics and its application in the field of cancer therapy has been broadly evaluated. A number of various liposomal formulations loaded with anti-cancer agents have been shown to deliver the drug at the site of solid tumors with minimum toxicity when compared to free drug. Several techniques have been tried to improve the efficiency of liposomes such as site-specific drug delivery in tumor [3], long circulation, improved loading and triggered release for delivery of anti-cancer agent to the tumor site. Amongst various modifications of liposomes, active targeting and passive targeting are strategies majorly employed till date. The most recent approach for cancer therapy using liposome is active targeting along with other approaches, e.g., stimuli sensitivity. For active targeting of liposomes, they are decorated with various targeting ligands such as antibodies, and their fragments, peptides, aptamer etc. (figure 1). Surface functionalization and modification of liposomes helps delivery of therapeutic drug specifically to solid tumors where the targeted liposomes can recognize tumor cells, can lead to endocytosis and therapeutic response after binding to targeting receptor.

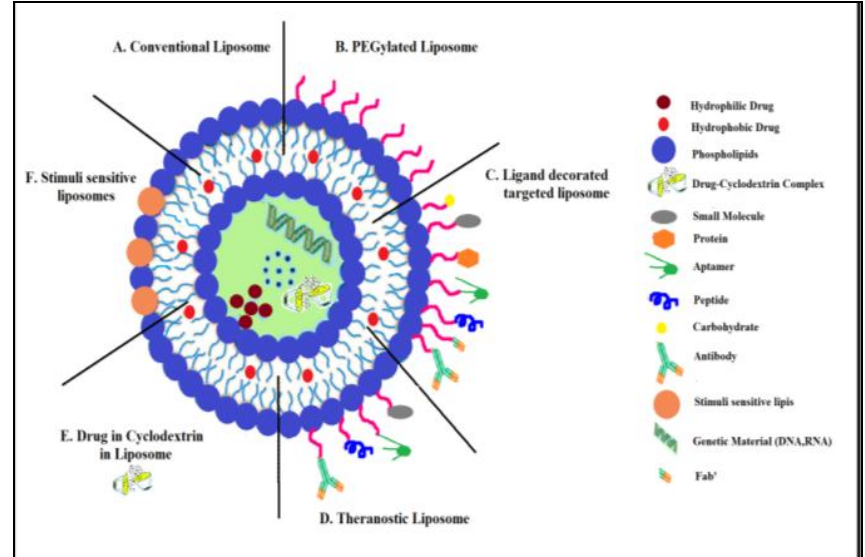

Fig. 1: Graphical representation of liposomal drug delivery systems and their modifications.

Table 1: Key liposomal formulations in clinic as well as in market for treatment of cancer.

\begin{tabular}{|c|c|c|c|c|c|}
\hline Type of Liposome & Active Ingredient & Indication & Clinical Status & Company & Reference \\
\hline \multicolumn{6}{|c|}{ Marketed Liposomal Products } \\
\hline Conventional & $\begin{array}{c}\text { Daunorubicin } \\
\left.\text { (DaunoXome }{ }^{\circledR}\right)\end{array}$ & AIDS-related Kaposi's sarcoma & $\begin{array}{l}\text { Approved } \\
\text { (1996) }\end{array}$ & NeXstar Pharma. & {$[\underline{4}]$} \\
\hline Conventional & Doxorubicin (Myocet ${ }^{\circledR)}$ & $\begin{array}{c}\text { Combination therapy with } \\
\text { cyclophosphamide in metastatic } \\
\text { breast cancer }\end{array}$ & $\begin{array}{l}\text { Approved } \\
(2000)\end{array}$ & Elan Pharma. & [5] \\
\hline Conventional & Mifamurtide (Mepact $\left.{ }^{\circledR}\right)$ & $\begin{array}{l}\text { High-grade, resectable, non- } \\
\text { metastatic osteosarcoma }\end{array}$ & $\begin{array}{l}\text { Approved } \\
\text { (2004) }\end{array}$ & $\begin{array}{l}\text { Takeda } \\
\text { Pharmaceutical } \\
\text { Limited }\end{array}$ & [6] \\
\hline Conventional & Vincristine (Marqibo®) & Acute lymphoblastic leukaemia & $\begin{array}{l}\text { Approved } \\
\text { (2012) }\end{array}$ & $\begin{array}{l}\text { Talon } \\
\text { Therapeutics, Inc }\end{array}$ & [7] \\
\hline Conventional & $\begin{array}{l}\text { Verteporphin } \\
\text { (Visudyne }{ }^{\circledR} \text { ) }\end{array}$ & Choroidal neovascularisation & $\begin{array}{l}\text { Approved } \\
\text { (2002) }\end{array}$ & Novartis & [8] \\
\hline PEGylated & Irinotecan (Onivyde ${ }^{\mathrm{TM}}$ ) & $\begin{array}{l}\text { Combination therapy with } \\
\text { fluorouracil and leucovorin in } \\
\text { metastatic adenocarcinoma of } \\
\text { the pancreas }\end{array}$ & $\begin{array}{l}\text { Approved } \\
\text { (2015) }\end{array}$ & $\begin{array}{c}\text { Merrimack } \\
\text { Pharmaceuticals } \\
\text { Inc. }\end{array}$ & [9] \\
\hline PEGylated & Doxorubicin (Doxil®) & $\begin{array}{l}\text { Ovarian, breast cancer, Kaposi's } \\
\text { sarcoma }\end{array}$ & $\begin{array}{c}\text { Approved } \\
(1995)\end{array}$ & $\begin{array}{c}\text { Sequus } \\
\text { Pharmaceuticals }\end{array}$ & [10] \\
\hline \multicolumn{6}{|c|}{ Liposomes in clinical trials } \\
\hline Conventional & Paclitaxel (LEP-ETU) & $\begin{array}{c}\text { Advanced triple-negative breast } \\
\text { cancer }\end{array}$ & Phase I/II & - & [11] \\
\hline Conventional & SiRNA & $\begin{array}{l}\text { Ovarian cancer } \\
\text { Acute promvelocytic leukemia }\end{array}$ & Phase I & - & [12] \\
\hline Conventional & Tretinoin & $\begin{array}{l}\text { and } \\
\text { hormone-refractory prostate } \\
\text { cancer }\end{array}$ & Phase II & - & {$[\underline{13}],[\underline{14}]$} \\
\hline Conventional & Irinotecan SN-38 & Metastatic colorectal cancer & Phase I/II & - & [15], [16] \\
\hline Conventional & Annamycin & Acute lymphoblastic leukemia & Phase I/II & - & [17] \\
\hline Conventional & Lurtotecan & $\begin{array}{l}\text { Ovarian cancer, head, and neck } \\
\text { cancer }\end{array}$ & Phase I/II & - & {$[\underline{18}],[\underline{19}]$} \\
\hline Conventional & Vinorelbine & $\begin{array}{c}\text { Newly diagnosed or relapsed } \\
\text { solid tumors }\end{array}$ & Phase I & - & [20] \\
\hline Conventional & Topotecan & Advanced solid tumors & Phase 1/II & - & [21] \\
\hline PEGylated & $\begin{array}{l}\text { Thermosensitive } \\
\text { doxorubicin }\end{array}$ & $\begin{array}{l}\text { Chest wall recurrences of breast } \\
\text { cance }\end{array}$ & Phase I & - & [22] \\
\hline PEGylated & Irinotecan & $\begin{array}{l}\text { Advanced refractory solid } \\
\text { tumors and colorectal cancer }\end{array}$ & Phase I & - & [23] \\
\hline PEGylated & Camptothecin analog & Ovarian cancer & Phase I & - & [24] \\
\hline Cationic & Paclitaxel EndoTAG-1 & $\begin{array}{l}\text { Advanced triple-negative breast } \\
\text { cancer }\end{array}$ & Phase II & - & [19] \\
\hline PEGylated & $\begin{array}{l}\text { Thermosensitive } \\
\text { doxorubicin }\end{array}$ & Liver tumors & Phase III & - & [22] \\
\hline Cationic & Paclitaxel EndoTAG-1 & Pancreatic cancer & Phase II & - & [25] \\
\hline
\end{tabular}


Figure 1 is a graphical representation of various modifications of liposomal drug delivery systems while Table 1 lists some of the key liposomal formulations in clinic as well as in market for treatment of cancer.

\section{Liposomes in cancer therapy}

The conventional chemotherapy is injecting a free drug in either solution or suspension form and the strategy has demonstrated good clinical efficiency till today. However, due to non-specific biodistribution, the anticancer drugs produce severe side effects, resulting into a limitation of dose or termination of therapy. So, encapsulation of anti-cancer drugs in liposomes like nanoparticulate carrier can reduce its toxicity [2]. Liposomes are concentric bilayered vesicles in which an aqueous core is entirely enclosed by a membranous lipid bilayer mainly composed of natural or synthetic phospholipids which can encapsulate both hydrophilic and lipophilic drugs that have become popular as drug delivery systems owing to their efficiency, biocompatibility, non-immunogenicity, enhanced bioavailability of chemotherapeutic agents.

\section{Composition of Liposomes}

The major structural components of liposome [26] is "Phospholipids and Cholesterol. Liposomal membrane is made up of phospholipids. Phospholipids depending on their origin can be classified as natural and synthetic. Phospatidylocholine is the most widely used phospholipid in formulation of liposomes which has amphipathic in nature. The other component, cholesterol by itself has no ability to form a bilayer membrane however it acts as fluidity buffer. It can change the freedom of motion of carbon molecules in the acyl chain after intercalating with phospholipids and thus increases separation between choline head groups in the membrane which reduces the normal hydrogen bonding and electrostatic interaction."

\section{Classification of liposomes}

Liposomes has been classified based on their structure parameters such as vesicle size, based on method of preparation and based on the composition and application. [27] Table 2 and 3 describe about classification of liposomes based on three various parameters.

\section{Advantages of liposomes}

- It offers site active targeted specific drug delivery to tumor hence eradicate non-specific biodistribution related side effects of chemotherapeutic drug.

- Increased efficacy and therapeutic index of drug after encapsulation in liposome as compared to free drug.

- Reduced volume of distribution and extends blood circulation time specifically for PEGylated liposomes.

- It is non -toxic, biocompatible, flexible, and completely biodegradable.

- Liposomes provide less exposure of anti-cancer drug to sensitive and healthy cells.
- It can encapsulate molecules with various size range and $\log \mathrm{P}$.

- $\quad$ Ease of administration through different routes.

Table 2: Classification of liposomes based on structural parameters and method of preparation.

\begin{tabular}{|c|c|c|c|}
\hline \multicolumn{2}{|c|}{$\begin{array}{c}\text { Based on structural } \\
\text { parameters }\end{array}$} & \multicolumn{2}{|c|}{ Based on method of preparation } \\
\hline Class & Specific size & Class & Specification \\
\hline SUV & $<0.1 \mu \mathrm{m}$ & REV & $\begin{array}{l}\text { Single or oligolamellar } \\
\text { vesicle made by } \\
\text { reverse phase evaporation } \\
\text { method }\end{array}$ \\
\hline LUV & $0.1-10 \mu \mathrm{m}$ & MLV-REV & $\begin{array}{l}\text { Multilamellar vesicle } \\
\text { made by reverse } \\
\text { phase evaporation } \\
\text { method }\end{array}$ \\
\hline MLV & $0.1-0.3 \mu \mathrm{m}$ & SPLV & $\begin{array}{l}\text { Stable plurilamellar } \\
\text { vesicle }\end{array}$ \\
\hline GUV & $>1 \mathrm{~mm}$ & FATMLV & Frozen and thawed MLV \\
\hline MVV & $>1 \mathrm{~mm}$ & VET & $\begin{array}{l}\text { Vesicle prepared by } \\
\text { extrusion technique }\end{array}$ \\
\hline OLV & $\begin{array}{l}\text { Intermediate } \\
\text { between MLV } \\
\text { and LUV }\end{array}$ & DRV & $\begin{array}{l}\text { Dehydration rehydration } \\
\text { method }\end{array}$ \\
\hline
\end{tabular}

Table 3: Classification based on composition and application

\begin{tabular}{cc}
\hline Class of liposome & Specification \\
\hline Conventional & $\begin{array}{c}\text { Made up of neutral or anionic phospholipid } \\
\text { hence mostly is neutral or negatively charged } \\
\text { formulation }\end{array}$ \\
$\begin{array}{c}\text { Cationic } \\
\text { PEGylated Long } \\
\text { circulatory }\end{array}$ & $\begin{array}{c}\text { Made up of cationic lipid e.g. DOTAP } \\
\text { Imparts long circulation and EPR effect }\end{array}$ \\
Immunoliposome & Made up of phospholipid like Phosphatidyl \\
ethanolamine
\end{tabular}

\section{Method of preparation of liposome}

Liposome may be prepared by mainly following techniques [7]

1. Passive loading technique

A) Mechanical dispersion method

- Lipid hydration - by hand shaking or freeze drying method

- Micro emulsification

- Sonication

- French pressure cell

- Membrane extrusions

- Dried reconstituted vesicle

- Freeze thawed liposome

B) Solvent dispersion method

- Ethanol injection

- Ether injection

- Double emulsion vesicle

- Reverse phase evaporation vesicle

- Stable plurilamellar vesicle

C) Detergent removal method

- Detergent such as cholate, alkylglycoside, Triton $\mathrm{x}-100$ etc. removal from mixed micelles

- Dialysis 


\section{- Column chromatography \\ - Dilution.}

2. Active loading technique.

\section{Various Surface Funtionalization and Modification strategies of Liposomes \\ PEGylated liposomes}

The technique of covalenty attaching polyethylene glycol (PEG) to liposomes is known as "PEGylated liposomes". Also known as Long Circulatory Liposomes OR Stealth Liposomes and is now a wellestablished method in the field of targeted drug delivery systems.

\section{Need for PEGylation}

PEGylation enhances the therapeutic efficacy of the drugs by incorporating several advantageous modifications over the non-PEGylated products. The major way of enhancement of therapeutic potential of the PEGylated conjugate is increase in the serum halflife of the conjugate and prolongs the circulation time of conjugated therapeutics by increasing its hydrophilicity and reducing the glomerular filtration rate. It provides protection from reticuloendothelial cells, proteolytic enzymes and reduced formation of neutralizing antibodies against the protein by masking antigenic sites by formation of a protective hydrophilic shield which attributes to the improved pharmacokinetic profile (PK) of the conjugates. It has been reported that PEGylation also increases the absorption half-life of subcutaneously administered agents and associated with a decreased volume of distribution.

\section{Mechanism of PEGylated liposomes}

PEGylated liposomes can passively accumulate inside other tissues or organs called as passive targeting, which is especially evident in solid tumors undergoing angiogenesis (the presence of a discontinuous endothelial lining in the tumor vasculature). During angiogenesis, PEGylated liposomes facilitates extravasation of liposomal formulations into the interstitial space, where they accumulate due to the lack of efficient lymphatic drainage of the tumor and functions as a sustained drug-release system which causes the preferential accumulation of liposomes in the tumor region (a process known as enhanced permeation and retention effect or EPR). Liposomal formulations do not cause extravasation from the bloodstream into normal tissues that have tight junctions between capillary endothelial cells. This mechanism appears to be responsible for the improved therapeutic effects of liposomal anticancer drugs vs free drugs. However, the processes involved in delivery of this carrier and release of anti cancer agent, the variability of such processes, and the degree to which the active agent is released into the tumor's extracellular fluid or into tumor cells, are still unknown. Doxil ${ }^{\circledR}$ is a formulation containing Doxorubicin hydrochloride which is the first FDA- approved nano drug delivery system based on PEGylated liposome technology. Originally Doxil ${ }^{\circledR}$ was developed in 1995 by Sequus Pharmaceuticals, USA as an i.v. injection for the management of advanced ovarian cancer, multiple myeloma and HIV-associated Kaposi's sarcoma. [14-2ㄹ].

\section{Drug in cyclodextrin in liposomes}

Drug in cyclodextrin in liposomes was reported in 1994 in the area of drug delivery which takes benefits of definite characteristics of liposomes and cyclodextrin (CDs) and combine them in a single system to overcome limitations associated with both the systems. This concept allows entrapment of water soluble cyclodextrin inclusion complex (IC) of water insoluble drugs such as PTX (paclitaxel) in aqueous core of liposomes. However, the volume of aqueous core is very low compared to the volume of bilayer which limits the entrapment beyond a certain theoretical limit. This strategy proposed to be promising in enhancing loading efficiency. So, in order to increase the drug load, encapsulation of drug in both bilayer and core of liposome, double loading of liposomes was proposed. Such double loading approach also seems to control in vivo fate of hydrophobic drugs, increase stability of vesicle and prolonging the release profile. [29, 30, 31]

\section{Immunoliposomes}

The concept of targeting liposomes to cells by attaching targeting ligands such as antibodies, fragment antigen binding $\left(\mathrm{Fab}^{\prime}\right)$, single-chain fragment variable $(\mathrm{scFv})$ fragments, or peptides to the liposomal surface is known as Immunoliposomes (ILs) for targeted drug delivery in cancer therapy

\section{Need for Active Targeting}

The high stability of liposomes which leads to poor and slow release of drug and might be associated with the low cellular uptake efficiency of liposomes. To overcome this obstacle, "Active Targeting" or ligandbased targeting has been emerged as one of the most promising strategies to improve internalization of specific drug. In this approach, targeted liposomes have ability to directly bind to cancer cells. For this, the surface of the liposomal formulations has to be attached with different types of ligands, which recognizes and bind those specific molecules expressed or overexpressed on the surface of cancer cells.

\section{Method of preparation}

Immunoliposomes (ILs) represents a newer strategy that has been widely investigated in preclinical cancer models with promising results, although few have reached the stage of clinical trials. ILs allows the conjugation of different targeting ligands such as mAbs or antibody derivatives like monovalent variable fragments of Fab', to the polymers covering the surface of liposomes. The combination of this targeting strategy together along with drug encapsulation in a single formulation may contribute to enhance the efficacy of these associated agents by minimizing their toxicities. Hence, the main strategy that has been adopted for formulation of targeted liposomes is the use of an end- 
functionalized pegylated lipid. This lipid derivative is able to form a covalent bond with the ligands sch as mAbs, which normally requires previous activation or modification. These coupling methods (eg, using thiolated antibodies coupled to maleimide (Mal)-PEG lipids or using modified amino-reactive PEG lipids) in random fashion risk antibody inactivation and liposome aggregation by cross- linking which results into whole antibodies possess several disadvantages for the generation of ILs. These disadvantages can be avoided by the use of antibody fragments such as fragment antigen binding (Fab') or single-chain fragment variable $(\mathrm{scFv})$ fragments.

\section{Fab' fragments}

Fab' fragments have been broadly investigated for drug delivery with sterically stabilized ILs (SILs). A direct comparison of Fab'-SILs and IgG-SILs results into reduced immunogenicity and also improve pharmacokinetics, as shown in comparative animal study of doxorubicin-loaded sterically stabilized antiGD2 ILs for the treatment of metastatic neuroblastoma which shows clearance of Fab'- SILs was similar to that of PEGylated liposomes, while IgG- SILs showed approximately 3-fold faster elimination. These Fab'SILs also proven to exhibit potent antitumor activity.

\section{scFv fragments}

$\mathrm{scFv}$ fragments are the smallest fragments that contains the entire antigen-binding site of an antibody. Human $\mathrm{scFv}$ fragments have been employed for the production of various ILs and to deliver drugs to target cells. For e.g.,, Using anti-HER-2 scFv-SILs, maximal binding was observed with 30 to $40 \mathrm{scFv}$ molecules attached. Doxorubicin-loaded anti-HER-2 scFv-SILs based on this formulation are currently produced under a GMPcompliant for preclinical process. Binding of these ILs to cells is a highly efficient process which requires only a few scFv molecules coupled to the liposomes One or more additional cysteine residues are attached to the Cterminus of $\mathrm{scFv}$ fragments in order to achieve coupling to liposomes which allows site-directed conjugation, with the reactive sulfhydryl group(s) located opposite the antigen-binding site. Thus, conjugation of this $\mathrm{scFv}$ fragments does not interfere with target cell recognition in comparison to coupling of Fab' fragments. Therefore, scFv molecules are well established that have been used by several research groups for the generation of targeted liposomes. $[\underline{32}, \underline{33}, \underline{34}$, 35]

\section{Triggered release/stimuli sensitive liposomes}

Stimuli cause instability to the liposomes leading to the release of entrapped material. Therefore, the concept of stimuli sensitivity have been developed which is based on certain characteristics of the tumor microenvironment, including a lower $\mathrm{pH}$, higher temperature and overexpression of several proteolytic enzymes. The stimuli-sensitive liposomes have ability to maintain their structure and physical properties throughout circulation. However, they are designed to undergo rapid changes (aggregation, disruption and permeability) that trigger drug release when exposed to a particular tumor microenvironment by utilizing either internal stimuli that are characteristic for a tumor microenvironment or externally applied stimuli, such as magnetic fields, ultrasound or light, for targeting tumor tissues. $[\underline{34}]$

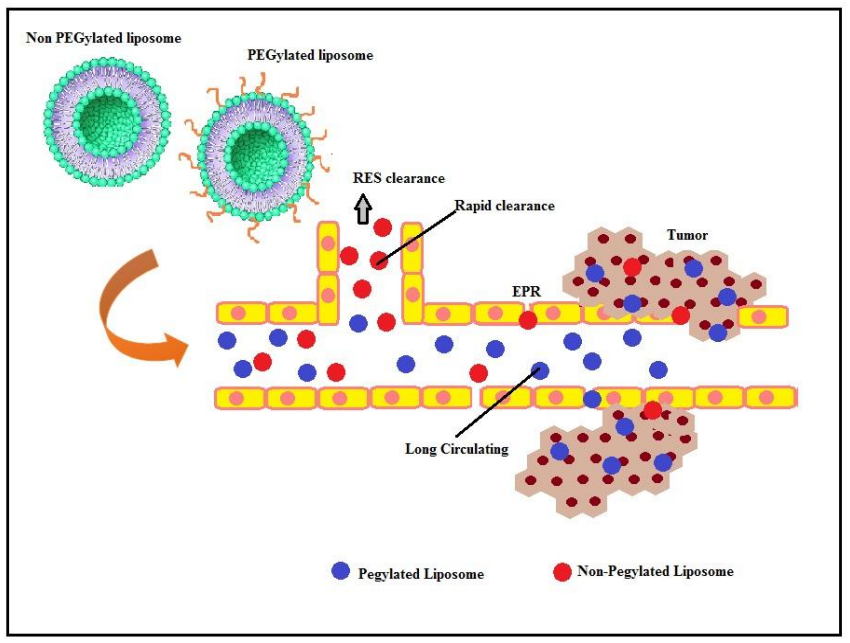

Fig. 2: In vivo fate of PEGylated liposomes and Non-PEGylated liposomes for cancer therapy.

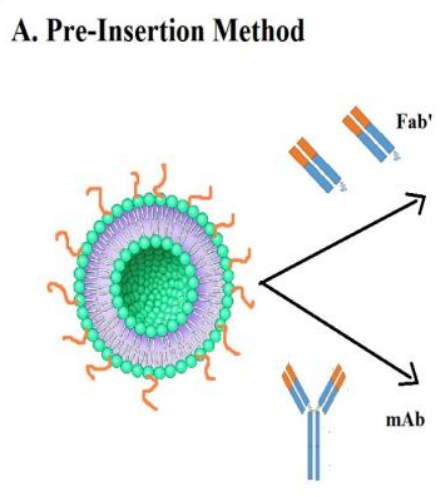

B. Post-Insertion Method
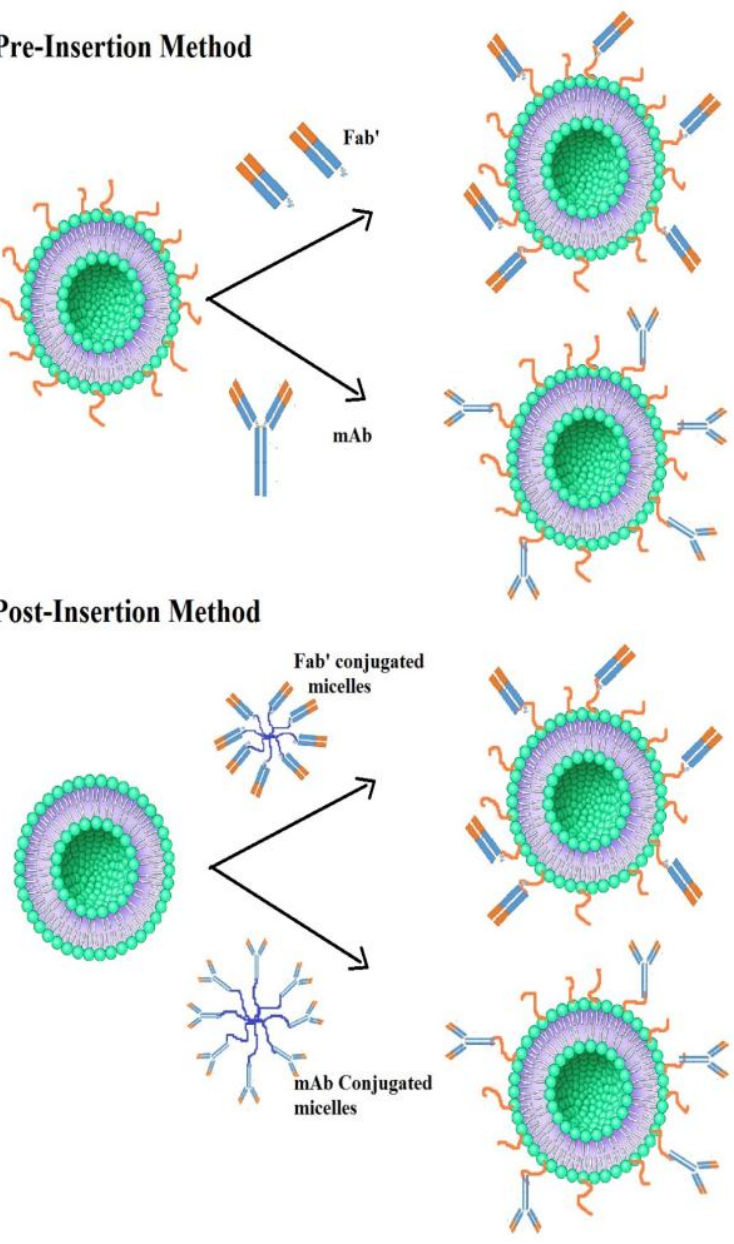

Immunoliposomes

Fig. 3: Methods of surface modification for development of Immunoliposomes coupled to $\mathrm{mAb}$ or $\mathrm{Fab}^{\prime}$-fragment as targeting ligands. A) Pre-Insertion Method, B) Post-Insertion Method. 


\section{pH-triggered drug delivery}

Although, PEGylation of liposomes is a desired modification which provides long circulation period in the blood but sometimes the PEG chains act as barriers to intracellular delivery or release of drugs. In the case of endocytosis, the PEG brush may sometimes results into the escape of liposomes from endosomes which results in degradation of their contents. To overcome this problem, labile linkages have been introduced between the hydrophilic PEG and the hydrophobic moiety such as a lipid that is cleaved only upon exposure to the relatively acidic conditions characteristic of the endocytic vacuole or the acidotic tumor mass. Also, pH-sensitive copolymers can be incorporated in the liposomes to provide shielding. Diortho esters, vinyl esters, cysteine-cleavable lipopolymers, double esters and hydrazones are a few examples of $\mathrm{pH}$-sensitive bonds which are quite stable at $\mathrm{pH}$ 7.5, but are hydrolyzed relatively rapidly at $\mathrm{pH} 6$ and below. The $\mathrm{pH}$-sensitive liposomal carrier releases the entrapped payloads in tissues with a low $\mathrm{pH}$, such as tumors, the cell cytoplasm or endosome. Liposomes made of $\mathrm{pH}$-sensitive components fuse with the endovascular membrane after endocytosis and subsequently release its contents into the cytoplasm under the action of low endosomal $\mathrm{pH}$.

\section{Temperature-triggered drug delivery}

Many pathological areas like inflamed tissues and tumors, shows a distinctive hyperthermia as compared to normal tissues. Hyperthermia is associated with increased tumor permeability and enhanced drug uptake and hence utilization of this hyperthermia is an attractive strategy in cancer therapy. This technique involves local heating at the tumor site to increase microvascular pore size and blood flow, which results in an increased extravasation of drug-loaded nanocarriers.

\section{Redox-triggered drug delivery}

The difference in redox potential between normal and tumor tissues and between the intra- and extra-cellular environments has been exploited for drug delivery in cancer. For example, L- glutathione (GSH), is reducing agent that are abundant in cells, especially in the cytosol, mitochondria and nucleus were GSH concentrations in blood and extracellular matrix are just one out of 100 to one out of 1000 of the intracellular concentration respectively. This high difference in redox potential caused by GSH, cysteine and other reducing agents can break the reducible bonds, cause destabilization of the liposomal system and release a payload. The disulfide bond has been used popularly as the cleavable/ reversible linker in liposomes, because it causes sensitivity to redox owing to the disulfide- to-thiol reduction reaction.

\section{Enzyme-triggered drug delivery}

Enzymes which are present in the tumor vasculature have been utilized as triggers to achieve site-specific drug delivery from stimuli-sensitive liposomes. Enzymes, including matrix metalloproteinases (MMPs) (e.g. MMP2), phospholipase A2, alkaline phosphatase, transglutaminase or phosphatidylinositol-specific phospholipase $\mathrm{C}$ etc., have been found to be overexpressed in tumor tissues. In the presence of these enzymes, enzyme-sensitive liposomes are degraded and release the encapsulated drug at the tumor site. Another approach is the use of a linker cleaved off in the presence of overexpressed enzymes, exposing other hidden functionalities.

\section{Light-triggered drug delivery}

Use of light for activation or inactivation of specific biochemical processes has been recognized as a promising tool for several biomedical applications. Among visible light, UV and near-infrared light used in the clinic, near-infrared is the most desirable for tumor targeting, since it penetrates deep into tissues. Photodynamic therapy has become a well-established tool for the treatment of superficial tumors, where photosensitizing agents, such as porphyrin derivatives, chlorins, phthalocyanines and porphycenes, are employed to sensitize and eradicate malignant cells. These agents generate radical oxygen species, which kill the targeted malignant tumor cells. Various lightsensitive lipids have been applied that facilitate phototriggered structural and conformational changes, which lead to direct interaction of liposomes with the target cells via membrane fusion, photo-isomerism, photofragmentation or photopolymerization.

\section{Ultrasound-triggered drug delivery}

Ultrasound-mediated drug delivery allows noninvasive penetration into deep tissues and can produce focused, controlled drug delivery. This concept is based on the enhanced permeability of blood capillaries, generation of thermal energy and the destruction of cell membranes due to microconvection or inertia cavitation. Ultrasound waves can induce both thermal and mechanical changes. Liposomes containing a small quantity of particular gases, including air or perfluorated hydrocarbon, were initially developed as an ultrasound contrast agent, but can be loaded with various drugs that are released after damage by an applied ultrasound treatment.

\section{Magnetic drug delivery}

'Magnetic colloids' can carry chemotherapeutic agents to target sites and maintain them at the site until the drug is completely released. To use an external magnetic field for tumor targeting, liposomes are magnetized by incorporation of magnetites, such as $\mathrm{Fe}_{3} \mathrm{O}_{4}$ or $\gamma-\mathrm{Fe}_{2} \mathrm{O}_{3}$ that are less than $10 \mathrm{~nm}$ in size. These liposomes have biomedical applications such as magnetic hyperthermia, magnetic transfection, and manipulation of cells and proteins. Owing to their superior magnetic properties and nanoscale size, they are also referred to as SPIONs. One approach for targeted drug delivery by exposure to a magnetic field is the use of liposomes loaded with a drug and a ferromagnetic material. $[36,37]$

Future perspective 
Liposomes have been revolutionized themselves in nanocarriers-based targeted drug delivery systems through their broad successful clinical applications of cancer therapy. The limitations of conventional chemotherapy for cancer therapy can be overcome by improving the bioavailability and stability of the anticancer drug molecules and minimizing side effects through site- specific targeted delivery of the drugs. Recently numbers of liposomal drug delivery systems for cancer therapy are already in the market and many more are undergoing research and clinical trials. Moreover, with new targets, advanced strategies and evaluation, the application of liposomes have been broaden to novel therapeutic concepts in cancer therapy, e.g. vascular targeting and gene silencing(antisense) approaches. Thus, it clears that in future liposomes will complement the therapeutic array for fighting against cancer.

\section{REFERENCES}

1. Fitzmaurice C, Dicker D, Pain A, Hamavid H, Moradi-Lakeh M, MacIntyre MF, et al. The Global Burden of Cancer 2013. JAMA Oncol. 2015;1:505-27.

2. Bhardwaj A, Srivastava SK, Singh S, Arora S, Tyagi N, Andrews J, et al. CXCL12/CXCR4 signaling counteracts docetaxel-induced microtubule stabilization via p21activated kinase 4-dependent activation of LIM domain kinase 1. Oncotarget. 2014;5:11490-500.

3. Bhatt P, Vhora I, Patil S, Amrutiya J, Bhattacharya C, Misra A, et al. Role of antibodies in diagnosis and treatment of ovarian cancer: Basic approach and clinical status. J Control Release. 2016;226:148-67.

4. Richardson DS, Kelsey SM, Johnson SA, Tighe M, Cavenagh JD, Newland AC. Early evaluation of liposomal daunorubicin (DaunoXome, Nexstar) in the treatment of relapsed and refractory lymphoma. Invest New Drugs. 1997;15:247-53.

5. Batist G, Barton J, Chaikin P, Swenson C, Welles L. Myocet (liposome-encapsulated doxorubicin citrate): a new approach in breast cancer therapy. Expert Opin Pharmacother. 2002;3:1739-51.

6. Takeda to Acquire IDM Pharma, Adding MEPACT (Mifamurtide), the First Treatment Approved for Osteosarcoma in More Than 20 Years.

7. Silverman JA, Deitcher SR. Marqibo(R) (vincristine sulfate liposome injection) improves the pharmacokinetics and pharmacodynamics of vincristine. Cancer Chemother Pharmacol. 2013;71:555-64.

8. Guidelines for using verteporfin (Visudyne) in photodynamic therapy for choroidal neovascularization due to age-related macular degeneration and other causes: update. Retina. 2005;25:119-34.

9. Merrimack and Baxalta Announce Publication of the ONIVYDETM (irinotecan liposome injection) NAPOLI-1 Study in The Lancet.

10. Patel J. Liposomal doxorubicin: Doxil®. Journal of Oncology Pharmacy Practice. 1996;2:201-10.

11. Zhang JA, Anyarambhatla G, Ma L, Ugwu S, Xuan T, Sardone $\mathrm{T}$, et al. Development and characterization of a novel Cremophor EL free liposome-based paclitaxel (LEP-ETU) formulation. Eur J Pharm Biopharm. 2005;59:177-87.

12. Mangala LS, Han HD, Lopez-Berestein G, Sood AK Liposomal siRNA for ovarian cancer. Methods Mol Biol. 2009;555:29-42.

13. Ozpolat B, Lopez-Berestein G, Adamson P, Fu CJ, Williams $\mathrm{AH}$. Pharmacokinetics of intravenously administered liposomal all-trans-retinoic acid (ATRA) and orally administered ATRA in healthy volunteers. J Pharm Pharm Sci. 2003;6:292-301.
14. Immordino ML, Dosio F, Cattel L. Stealth liposomes: review of the basic science, rationale, and clinical applications, existing and potential. International Journal of Nanomedicine. 2006;1:297-315.

15. Zhang JA, Xuan T, Parmar M, Ma L, Ugwu S, Ali S, et al. Development and characterization of a novel liposome-based formulation of SN-38. Int J Pharm. 2004;270:93-107.

16. Suenaga M, Mizunuma N, Matsusaka S, Shinozaki E, Ozaka $\mathrm{M}$, Ogura $\mathrm{M}$, et al. Phase II study of reintroduction of oxaliplatin for advanced colorectal cancer in patients previously treated with oxaliplatin and irinotecan: RE-OPEN study. Drug Des Devel Ther. 2015;9:3099-108.

17. Wetzler M, Thomas DA, Wang ES, Shepard R, Ford LA, Heffner TL, et al. Phase I/II trial of nanomolecular liposomal annamycin in adult patients with relapsed/refractory acute lymphoblastic leukemia. Clin Lymphoma Myeloma Leuk. 2013;13:430-4.

18. Dark GG, Calvert AH, Grimshaw R, Poole C, Swenerton K, Kaye $\mathrm{S}$, et al. Randomized trial of two intravenous schedules of the topoisomerase I inhibitor liposomal lurtotecan in women with relapsed epithelial ovarian cancer: a trial of the national cancer institute of Canada clinical trials group. J Clin Oncol. 2005;23:1859-66.

19. Chang H-I, Yeh M-K. Clinical development of liposomebased drugs: formulation, characterization, and therapeutic efficacy. International Journal of Nanomedicine. 2012;7:49-60.

20. Allen TM, Cullis PR. Liposomal drug delivery systems: from concept to clinical applications. Adv Drug Deliv Rev. 2013;65:36-48

21. Seiden MV, Muggia F, Astrow A, Matulonis U, Campos S, Roche M, et al. A phase II study of liposomal lurtotecan (OSI211) in patients with topotecan resistant ovarian cancer. Gynecol Oncol. 2004;93:229-32.

22. Yarmolenko PS, Zhao Y, Landon C, Spasojevic I, Yuan F, Needham D, et al. Comparative effects of thermosensitive doxorubicin-containing liposomes and hyperthermia in human and murine tumours. Int $\mathrm{J}$ Hyperthermia 2010;26:485-98.

23. Chang TC, Shiah HS, Yang $\mathrm{CH}$, Yeh $\mathrm{KH}$, Cheng $\mathrm{AL}$, Shen $\mathrm{BN}$, et al. Phase I study of nanoliposomal irinotecan (PEP02) in advanced solid tumor patients. Cancer Chemother Pharmacol. 2015;75:579-86.

24. Zamboni WC, Ramalingam S, Friedland DM, Edwards RP, Stoller RG, Strychor S, et al. Phase I and pharmacokinetic study of pegylated liposomal CKD-602 in patients with advanced malignancies. Clin Cancer Res. 2009;15:1466-72.

25. Lohr JM, Haas SL, Bechstein WO, Bodoky G, Cwiertka K, Fischbach W, et al. Cationic liposomal paclitaxel plus gemcitabine or gemcitabine alone in patients with advanced pancreatic cancer: a randomized controlled phase II trial. Ann Oncol. 2012;23:1214-22.

26. Liposome: A versatile platform for targeted delivery of drugs." Shri B. M. Shah College of Pharmaceutical. Sanjay S. Patel (M. Pharm), 2006.

27. Deshmukh RR, Gawale SV, Bhagwat MK, Ahire PA, Derle ND. A review on: liposomes. WJPPS. 2016; 5(3):506-517.

28. Haley B, Frenkel E. Nanoparticles for drug delivery in cancer treatment. Urologic oncology. 2008;26:57-64.

29. Bhatt P, Lalani R, Vhora I, Patil S, Amrutiya J, Misra A, et al. Liposomes encapsulating native and cyclodextrin enclosed paclitaxel: Enhanced loading efficiency and its pharmacokinetic evaluation. International Journal of Pharmaceutics. 2018;536:95-107.

30. Dhule SS, Penfornis P, Frazier T, Walker R, Feldman J, Tan G, et al. Curcumin-loaded gamma-cyclodextrin liposomal nanoparticles as delivery vehicles for osteosarcoma. Nanomedicine. 2012;8:440-51.

31. McCormack B, Gregoriadis G. Entrapment of cyclodextrindrug complexes into liposomes: potential advantages in drug delivery. J Drug Target. 1994;2:449-54.

32. Bhatt $P$, Lalani R, Mashru R, Misra A. Abstract 2065: AntiFSHR antibody Fab' fragment conjugated immunoliposomes loaded with cyclodextrin-paclitaxel complex for improved in 
R. K Jani et al. / Liposomal Formulations in Cancer Therapy: Basic Concepts to Advanced Strategies...........

vitro efficacy on ovarian cancer cells. Cancer Research. 2016; 76(14):2065.

33. Vhora I, Patil S, Bhatt P, Misra A. Protein- and Peptide-drug conjugates: an emerging drug delivery technology. Adv Protein Chem Struct Biol. 2015; 98:1-55.

34. Vhora I, Patil S, Bhatt P, Gandhi R, Baradia D, Misra A. Receptor-targeted drug delivery: current perspective and challenges. Ther Deliv. 2014; 5:1007-24.
35. Sawant RR, Torchilin VP. Challenges in development of targeted liposomal therapeutics. AAPS J. 2012; 14:303-15.

36. Zhu L, Kate P, Torchilin VP. Matrix metalloprotease 2responsive multifunctional liposomal nanocarrier for enhanced tumor targeting. ACS Nano. 2012; 6:3491-8.

37. Sawant RR, Torchilin VP. Liposomes as 'smart' pharmaceutical nanocarriers. Soft Matter. 2010; 6:4026-44.

HOW TO CITE THIS ARTICLE: Jani RK, Gohil KM. Liposomal Formulations in Cancer Therapy: Basic Concepts to Advanced Strategies. Int. J. Pharm. Sci. Drug Res. 2018; 10(5): 386-393. DOI: 10.25004/IJPSDR.2018.100505 